\title{
Natural Steam Power Developments at Larderello.
}

TWHE problem of utilising the earth's internal heat is no new one, but the general attention of scientific.workers and of technologists has been directed to this most interesting topic in a more special manner during these last few years, since a practical application of geothermal energy has been successfully achieved at the Boracic Works of Larderello, in the neighbourhood of Larderello, in Tuscany. This plant, which was originated and brought to its present satisfactory state of development by Prince Piero Ginori Conti, was briefly described in Nature of Jan. 12, 1924. A few additional details as to further results obtained will only efficient source of natural heat supply. Very interesting discussions have arisen as to the origin of natural steam such as occurs in California, Oregon, Chile, New Zealand, Java, and Tuscany, where steam springs or fumaroles appear to be a phenomenon allied to vulcanism, but not entailing the immediate neighbourhood of a volcano. Thus, for example, the Tuscan soffioni appear to be connected with the trachitic eruptions which took place in central Italy in the latter part of the Tertiary Period, but the traces of these eruptions are found at considerable distances from the spots where the fumaroles are situated. These fumaroles

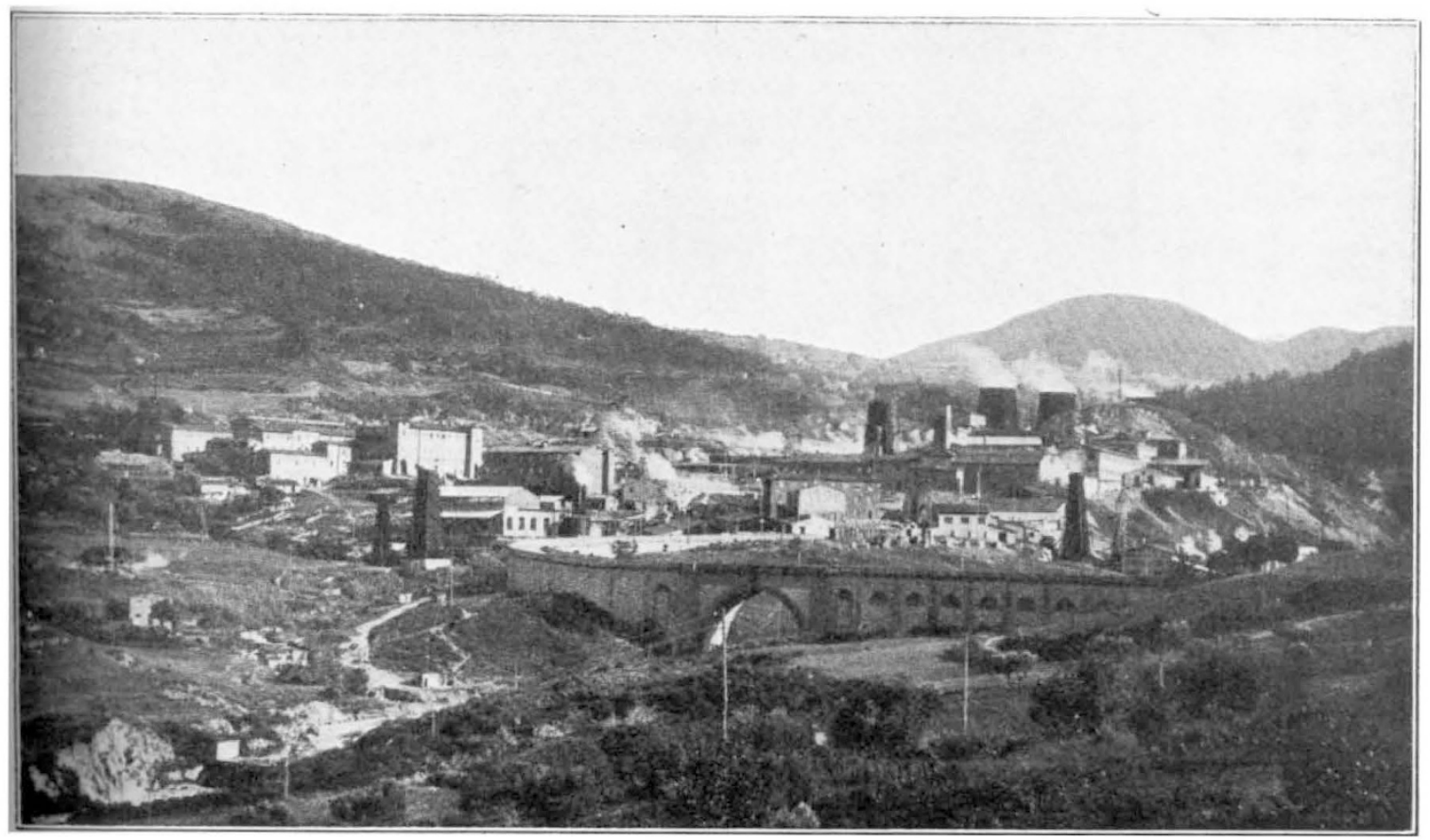

FIG. 1.-General view of the Larderello works.

doubtless be welcomed by many readers of this journal.

The fumaroles of Tuscany, better known under the local denomination of soffioni, are a notable example of the only form of volcanic activity which is suitable for exploitation, active volcanoes being evidently quite out of the question-at least so far as our present means are concerned. It has been proposed to sink tubes into the hot soil surrounding certain volcanoes, but such schemes do not appear to be practical, as experience has proved that heat transmission, even from incandescent lava, is exceptionally poor, so that enormous heating surfaces would be required to obtain a sufficient quantity of heat to be worth utilising. This observation applies to schemes depending on the utilisation of the geothermal gradient, as by sinking wells to considerable depths in order to reach high temperatures.

Natural steam springs, or fumaroles, are therefore, at the present stage of our experience, the differ, therefore, from those which abound near Vesuvius, Etna, and several other active or quiescent volcanoes, notable among others being those of the "Valley of Ten Thousand Smokes" in Alaska, which issue from the imposing masses of matter erupted from the Katmai volcano, covering a very large area of territory. This latter class of fumaroles is less accessible to investigation, but in some cases, such as the solfatara of Pozzuoli near Naples (which is not in the immediate vicinity of Vesuvius, but situated in the crater of an extinct volcano), experiments can be made. A scheme for utilising the solfatara of Pozzuoli is being studied.

Modern theories as to the internal structure of our planet lead us to consider that the origin of volcanic phenomena should be traced to magmatic deposits which underlie the upper crust of sedimentary rocks, and in some instances are situated at no very great depth below the surface. The steam which is present (either in its proper form, or dissociated in its component gases) in all volcanic

No. 3037, VoL. 121] 
manifestations is mainly the result of crystallisation of such glassy siliceous magma: phreatic or surface waters, penetrating to adequate depths, are in many cases present and condense the magmatic steam, thus forming almost all the ordinary thermal springs, though the presence of phreatic or surface waters can be traced also in the steam of fumaroles. This theory is supported by geophysical evidence, and has been amply illustrated and discussed in more than one instance, and notably in the case of the fumaroles and thermal springs which abound in the United States. Identical conclusions had been arrived at as a result of the geophysical studies carried out on the district surrounding Larderello, under the patronage of Prince Ginori Conti.

The soffioni of Tuscany have been utilised since 1818 for the extraction of boric acid, the presence

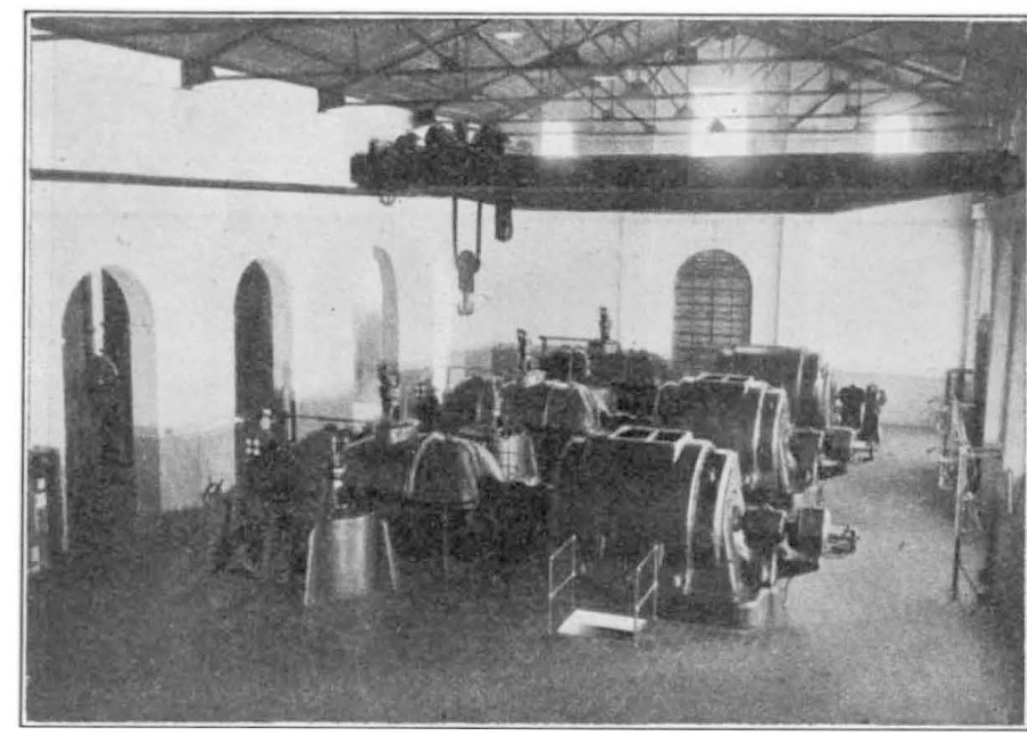

Fig. 2.-The turbine room at Larderello; three turbo-alternators of $2500 \mathrm{kw}$. each. The turbines are fed with volcanic steam which has been stripped of about 90 per cent, of the accompanying gases.

of which in the waters resulting from the condensation of the natural steam was discovered in 1777 , but the production of mechanical power by means of these soffioni was begun only in 1904 . The first machine with which Prince Ginori Conti made his experiments was a very small cylinder engine which he fed with the volcanic steam used, up to that date, only for heating purposes in connexion with the chemical works and especially with the apparatus for concentrating boric waters. This first experiment was a very important one, as it proved the possibility of working continuously in such conditions with an engine. A slightly larger engine was afterwards tried, with excellent results, and a further step was taken in 1913, when a $250-\mathrm{kw}$. turbine was installed.

The steam of the Tuscan soffioni, besides boric acid and other substances, including ammonia, is accompanied by a certain percentage of gases, mainly carbon dioxide, with minor quantities of hydrogen sulphide, some methane, hydrogen, nitrogen, and oxygen, and smaller quantities of argon and helium. The presence of such non-condensable gases would have proved a great hindrance to the efficiency of the condensing apparatus required in connexion with turbines, and it was therefore decided to heat, by means of the volcanic steam, appropriate evaporators generating pure steam for feeding the turbines. The same method was adopted when, in 1916 , three $2500-\mathrm{kw}$. turboalternators were put up at Larderello. This system, though theoretically correct, did not give very good results in practice on account of leakages often occurring in the evaporator tubes, through which the gases found their way into the turbines and the condensers, greatly reducing the vacuum which is essential to the efficiency of the low pressure turbines $(0.25 \mathrm{~atm}$. eff.) used at Larderello.

Considerable improvement was obtained by doing away with the evaporators and substituting, in their stead, special depurating apparatus which eliminates about 90 per cent. of the gas. Such depurators, which are extremely simple, are working most efficiently at the Larderello power station. The non-condensable gases are sent on through pipes to a special department of the chemical works, where carbon dioxide is separated and liquefied : part of it is used at Larderello, together with ammonia which is obtained from the volcanic steam, to make carbonate of ammonia. The depurators also yield a considerable amount of boric waters which are utilised in the chemical department, which, by concentrating the liquors and allowing the acid to crystallise by cooling, extracts boric acid.

More than $5000 \mathrm{kw}$. is now generated at the Larderello power station, but in the near future three units will be running instead of two, thus adding a further $2500 \mathrm{kw}$.

The Larderello wells were giving, in the beginning of 1927 , more than $120,000 \mathrm{kgm}$. of steam per hour, but quite recently an exceptionally powerful well was struck, yielding more than $60,000 \mathrm{kgm}$. of steam per hour at a pressure of 2 atm. eff., so that the supply of steam may be considered as superabundant until sufficient depurators and turbines are installed to deal with it. These very remarkable results are due to the improved methods of drilling which have been gradually introduced. The making of steam wells is an operation which calls for a very careful technique, which can only result from extensive practice in dealing with volcanic soil ; it is not exempt from risks, and skilled labour is required, as accidents are not uncommon, steam being sometimes found quite suddenly.

Regular drilling in the volcanic soil of Larderello was begun so far back as 1836, when steam was merely used for its boric acid content, but the old wells were of small depth and their diameters were

No. 3037, VoL. 121] 
also small. Gradual improvements were introduced and outputs of $25,000 \mathrm{kgm}$. per hour were obtained from single wells when the power station was built; but far better results followed about three years ago at the Castelnuovo works, about 3 miles south of Larderello, where about 60,000 $\mathrm{kgm}$. per hour were given out by a new well at $1 \mathrm{~atm}$. eff., while considerable outputs were available from the same well at a pressure of $3 \mathrm{~atm}$. At the older wells, the output falls rather rapidly as the pressure increases. The pressure of a well attains its maximum when the well is closed down, while the gradual opening of the head valve lowers the pressure as the output increases. Measures of output are made with different gauged tubes, thus allowing a diagram to be plotted showing the linear variation of output with variation of pressure.

The remarkable results of the Castelnuovo well (though not so brilliant as those which have since been obtained at Larderello, as recorded above), besides similar ones at other works, were responsible for the experiment of a small, direct feed, free exhaust turbine which was installed at the Serrazzano works and ran in the most satisfactory manner for more than a year. A further experiment was carried out at Castelnuovo in 1925 with a $650-\mathrm{kw}$. turbine, which has since been followed by two other $750-\mathrm{kw}$. units. The Castelnuovo plant is ideally simple, the impulse type turbines being fed directly with the soffioni steam: the steam enters the turbine at $2 \mathrm{~atm}$. and free exhaust pressure is about $0.1 \mathrm{~atm}$. All expensive and complicated condensing apparatus, with attendant paraphernalia of pumps, cooling towers, etc., are entirely done away with and exhaust steam is sent on to the chemical department for heating concentrating apparatus dealing with boric waters. During its progress from the turbines to the concentrators, the steam is ' washed,' that is, it is made to give up part of the boric acid which it carries. This operation is performed very simply by allowing a jet of water to enter the pipes conveying the steam, by means of an injector device; the water dissolves part of the boric acid and is extracted farther down along the piping. This operation, though not always performed in the case of steam used for power generation, is very extensively resorted to in other instances at the Larderello works and provides part of the boric waters used in the chemical department, the remainder being obtained from the soil where natural jets of steam partially condense.

The new Castelnuovo power station, in comparison with the Larderello plant, has a higher steam consumption per kilowatt-hour, but, on the other hand, cost of plant and expenses of running and upkeep are far lower. Each system has its advantages and, where considerations of expense are of paramount importance, while natural steam is abundant, the free exhaust system appears to be preferable.

At the present moment the total output of power generated by means of natural steam at the Tuscan Boracic Works is more than $6500 \mathrm{kw}$., with the three power stations of Larderello, Castelnuovo, and
Lago, the latter being only a small experimental plant generating about $200 \mathrm{kw}$. New plants are being studied, and it is confidently expected to attain a total power of at least $10,000 \mathrm{kw}$. The Società Boracifera di Larderello, which owns all the natural steam springs of the district, has eight different works for the extraction of boric acid, at all of which steam is more or less plentiful, and drillings are being actively carried on in most of these works.

Since the first publication, in 1918, of the results obtained by Prince Ginori Conti, other schemes of

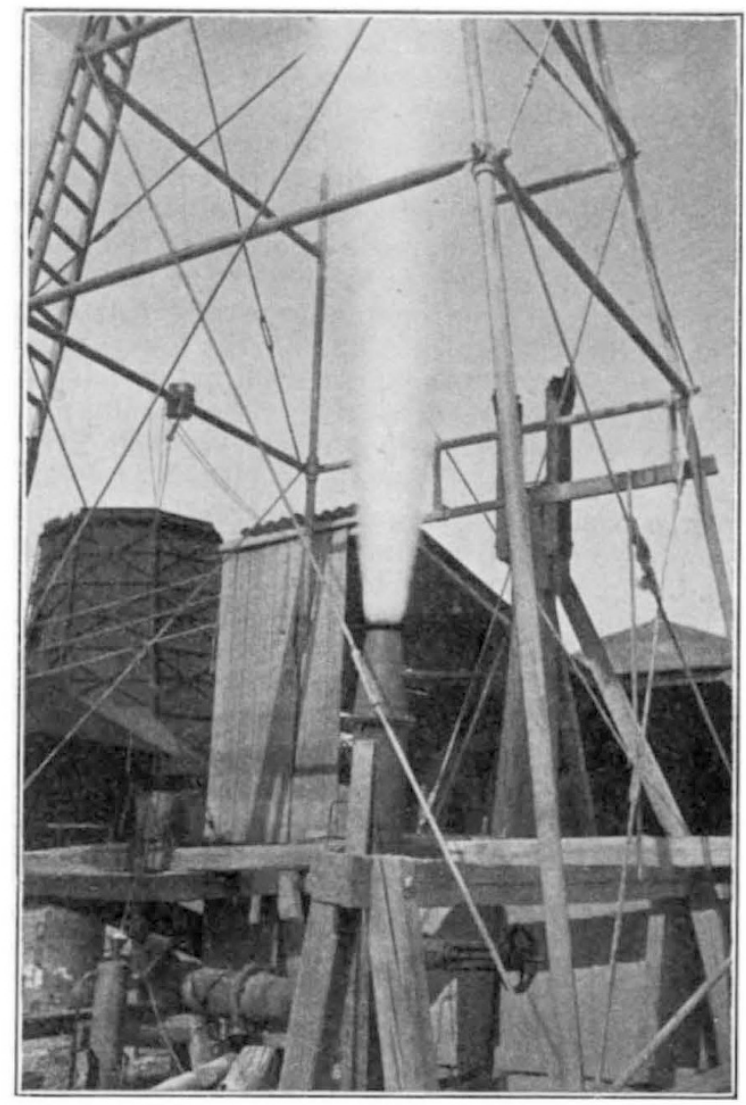

FIG. 3.-A powerful well at Larderello. This well gives more than $60,000 \mathrm{kgm}$. of steam per hour at 2 atm. efficiency. The steam is seen issuing from a gauged conical tube used for measuring the output of steam.

the same nature have been proposed in different parts of the world, notable among which is that for utilising the important steam springs of Sonoma County in California, commonly, but improperly, called ' geysers.' According to the reports published, the outputs of steam obtained there by drilling are quite notable, but, so far at least, no machinery of any importance has been installed. Other experiments are reported to be in progress in Java.

The Larderello plant is, however, the only concern in the world which is actually working and supplying power derived from natural heat. Larderello is distributing power to the region surrounding the works and is also running in parallel with

No. 3037, Vou. 121] 
the important hydroelectric stations which feed the main distribution lines of the western part of Tuscany.

Another striking feature of the Larderello geothermal plant is the utilisation of natural steam not only with regard to its heat contents but also on account of its chemical components. Power is, in fact, an intermediate product, boric acid and its derivates, carbonate of ammonia and carbon dioxide being the final products. From this point of view also, it is undeniable that the methods applied at Larderello constitute the first successful attempt at a complete and rational utilisation of the volcanic or pseudo-volcanic phenomena through which subterranean heat is brought within reach of human efforts.

\section{Parallel Evolution among Protophyta. ${ }^{1}$}

\section{By Prof. F. E. Fritsch.}

$\mathrm{T}$ HE present-day freshwater Algæ represent the most elementary types of holophytic plant-life to which we have access. The probability that such forms will ever be found preserved in the fossil state in sufficient numbers and showing the necessary details of cell-structure to be of any value for comparative morphological study or for the elucidation of the mode of origin of the multi: cellular plant, appears at the best to be remote.

The relation of the different types of construction that can be distinguished among the lower Protophyta to one another, and to the more elaborate parenchymatous soma usual in land-plants, must always remain in part a matter of conjecture. There are, however, certain definite facts which emerge from a comparative study of the simpler holophytic organisms and that have an important bearing on these problems.

It is now nearly thirty years since the doctrine of the flagellate origin of the Algæ became firmly established by the discovery in Sweden of Chloramœba and Chlorosaccus. These two simple forms agreed with a number of others in the possession of yellow-green chloroplasts containing an excess of xanthophyll and devoid of pyrenoids, the storage of oil, and the possession of a motor apparatus consisting of two very unequal cilia attached at the front end. These and other minor characteristics served to separate out from the extensive group of the Chlorophycere a small set of Algæ which became known by Luther's name, Heterokontæ (yellow-green Algæ). The remainder of the Chlorophyceæ were renamed Isokontæ, a designation based upon the fact that here the motile stages bear equal cilia (commonly 2 or 4 ). In the Isokontæ the chloroplasts are often large and few in number and are commonly provided with pyrenoids; they contain the same pigments as those of the higher plants and, so far as we know, in roughly the same proportions. Most Isokontæ, moreover, store starch.

Already at the end of last century practically every conceivable type of simple plant-body was known in the Green Algæ, ranging from the motile or motionless unicell, through manifold colonial forms, to a more or less highly elaborated filament. This extremely varied somatic development corresponds to a remarkable range of habitat and goes hand in hand with a great diversity in reproductive

1 From the presidential address to Section $\mathbf{K}$ (Botany) on "Some Aspects of the present-day Investigation of Protophyta," delivered on Sept. 1 at the Leeds meeting of the British Association. processes. There is in fact no other group of simple organisms showing such a wide scope in all these respects. By contrast the Heterokontæ, when first distinguished, included only relatively few forms. By degrees, however, many additional members have been discovered, and in the course of this century it has become increasingly apparent that there exists a far-going parallelism between these two classes, Isokontæ and Heterokontæ, which are so sharply segregated by their metabolism and other features that the vast majority of algal workers have regarded them as quite separate evolutionary lines, in no way related to one another.

The Heterokontæ do not, however, exhibit anything approaching the multiplicity of forms that are seen among the Isokonta; in particular they do not appear to have evolved the motile colony. The less vigorous development accords with the fact that only a few of the more specialised members of the class exhibit sexual reproduction and that this has not passed beyond the phase of isogamy.

The ciliated members of Heterokontæ without exception show 'flagellate' characteristics; that is to say, they are devoid of a cell-wall, their plasmamembrane (periplast) is more or less rigid but usually admits of some change of shape, multiplication is effected by longitudinal division, the protoplast readily encysts, and sexual reproduction is not known to occur. Some of the palmelloid members (e.g. Chlorosaccus), possibly all, also show these features. The many motile and palmelloid types among the Isokontæ are, on the other hand, for the most part on a higher plane of organisation and reproduction, being true Algæ provided with a firm cell-wall and usually exhibiting sexuality. When, however, the parallelism between the two classes is recognised, the distinction between flagellate and algal organisation loses force, and it is realised that the assumption of 'algal' characteristics has taken place at an earlier stage in the evolution of the one and at a later stage in that of the other.

These conclusions, however, do not apply only to Isokontæe and Heterokontæ. It is now clear that, in all the classes of pigmented Protophyta, an analogous evolutionary sequence has been followed, but that the features associated with what may be called 'algal organisation' have appeared, if at all, at different points in the sequence in the diverse classes. It is no longer feasible to separate the Algæ from the holophytic Flagellata as distinct

No. 3037, VoL. 121] 